\title{
Awareness and acceptance of contraception in post-partum women in a tertiary care hospital of Delhi
}

\author{
Meenakshi Singh ${ }^{1}$, Suman Mehla ${ }^{2},{\text { Rajesh } \operatorname{Ranjan}^{3} * \text {, Banashree Das }}^{4}$
}

\begin{abstract}
${ }^{1}$ Department of Obstetrics \& Gynecology, Lady Harding Medical College, New Delhi, India
${ }^{2}$ Department of Obstetrics \& Gynaecology, Sharda Medical College and Hospital, Greater Noida, Uttar Pradesh, India

${ }^{3}$ Department of Community Medicine, Mayo Institute of Medical Sciences, Gadia, Barabanki, Uttar Pradesh, India

${ }^{4}$ Department of Obstetrics \& Gynecology, VMMC and Safdarjung Hospitals, New Delhi, India
\end{abstract}

Received: 18 March 2015

Revised: 26 March 2015

Accepted: 19 April 2015

\author{
*Correspondence: \\ Dr. Rajesh Ranjan, \\ E-mail: rajesh.dr.ranjan@gmail.com
}

Copyright: () the author(s), publisher and licensee Medip Academy. This is an open-access article distributed under the terms of the Creative Commons Attribution Non-Commercial License, which permits unrestricted non-commercial use, distribution, and reproduction in any medium, provided the original work is properly cited.

\begin{abstract}
Background: India is second most populous country of the world and in next few decades it will cross china if it will keep on increase by this exponential growth. This calls for steps to stabilize India's population. India was the first country in the world to launch the Family Planning Programme in 1951. Despite this fact, India still lags behind in practicing contraception and limiting their family size.

Methods: A prospective cross-sectional interview based study was conducted on a sample of 492 post partum women who underwent their deliveries in this hospital in six months duration in the department of Obstetrics and Gynecology, Safdarjung Hospital, New Delhi. The women were counseled regarding post-partum contraception after assessment of their knowledge and practices. The interview included socio demographic profile of the participants, their awareness for contraceptive methods and reasons for its acceptance/refusal.

Results: Out of 492 post-partum women, $56.9 \%$ accepted one of the contraceptive methods during their hospital stay only. The most common contraceptive method chosen was intrauterine device $(45.0 \%)$. The main reason for nonacceptance of contraception was expectation of a male child.

Conclusions: Providing effective, high quality antenatal and post-partum contraceptive counseling can reduce unintended pregnancies, decrease maternal and fetal morbidity and mortality and prevent unsafe abortions. In order to improve the situation, health authorities should be encouraged to provide counseling on postpartum contraceptive methods during antenatal and immediate postpartum period.
\end{abstract}

Keywords: Postpartum, Counseling, Contraceptives, Awareness, Acceptance

\section{INTRODUCTION}

According to Census 2011, India with its population of 1210 million ranks $2^{\text {nd }}$ in world. The last decade has seen India's population grow by $17.64 \% .{ }^{1}$ This calls for steps to stabilize India's population. India was the first country in the world to launch the Family Planning Programme in 1951. Despite this fact, India still lags behind in practicing contraception and limiting their family size. Evidence shows that closely-spaced pregnancies pose health risks to mothers and newborns. An analysis of data from the Demographic and Health Survey (DHS) for various years shows that babies born less 2 years after the next oldest sibling were more than twice as likely to die in the first year compared to babies born after an interval of three years. ${ }^{2}$ Also, women with short inter-pregnancy intervals (less than 6 months) were at higher risk of maternal death $(\mathrm{OR}=2.54)$, third trimester bleeding $(\mathrm{OR}=1.73)$, premature rupture of membranes $(\mathrm{OR}=1.72)$ and anemia $(\mathrm{OR}=1.30){ }^{3}$ Family planning could prevent up to one- third of all maternal deaths by allowing 
women to delay motherhood, space births, avoid unintended pregnancies and unsafe abortions, and stop childbearing when they have reached their desired family size. $^{4}$

More than half a million women die each year as a result of complications related to pregnancy and childbirth in developing countries across the world. ${ }^{5,6}$ In India, there were 68000 maternal deaths in $2008 .^{7}$ Of the 7.7 million child deaths reported worldwide in $2010,22 \%$ occurred in India. ${ }^{5-8}$ Recent Indian National Family Health Survey (NFHS) data further show that $12 \%$ of children ever born to currently married women have died. ${ }^{8}$ Available studies demonstrate that the chances of infant and maternal survival would be 2.5 times as high with birth intervals of 3-5 years as with intervals of two or fewer years. ${ }^{9-12}$ In this context, the postpartum period is particularly important.

Despite the fact that contraceptive usage has increased over a period of time, there exists a KAP-gap i.e. a gap between the knowledge, attitude and practices regarding contraception. $^{13,14}$

Contraceptive demand is not constant throughout the reproductive life of a woman, postpartum period being the most crucial as appropriate birth spacing can improve the maternal and infant mortality rates. ${ }^{15}$ Family planning can reduce maternal mortality by reducing the number of pregnancies, the number of abortions, and the proportion of births at high risk. ${ }^{16,17}$ Almost one half of all pregnancies remain unintended. Indeed, more than one half of these end in termination. Quite a large number - to stress upon the critical need for those women who do not desire pregnancy, to be aware of and have access to the various methods of safe and effective contraception. The Immediate puerperium presents an ideal and important opportunity to initiate effective contraception. Present study is based on the assumptions that women are receptive to family planning education in post-partum period and they will not return to health centre for contraception once discharged from hospital. It is seizing a missed opportunity by ensuring that parturient women have received contraception before leaving hospital.

Newly parturient mothers are primarily concerned with their own and newborn's health. In addition, they are aware of a diminished risk of pregnancy during the period. Therefore this immediate post-partum period is most critical to counsel them and assure their contraceptive acceptance during their hospital stay in order to prevent unwanted pregnancy and unsafe abortion and curb population growth as well. Although Lactational Amenorrhoea Method (LAM) is an effective method but it is not practically feasible for all women. Transition from LAM to other modern contraceptive method poses another risk of accidental pregnancy. Immediate postpartum counseling in hospital ensures availability of husband who is major decision maker in most of the cases.

\section{METHODS}

A total of 600 postpartum women were enrolled out of which 108 were lost to follow up so only 492 women were finally enrolled. A cross-sectional interview based study was conducted on a sample of 492 post-partum women who underwent their deliveries in this hospital in six months duration in the department of obstetrics and gynecology, Safdarjung Hospital, New Delhi. The women were counseled regarding post-partum contraception after assessment of their knowledge and practices.

Counseling regarding contraception is being provided by counselors as well as the doctors in the department.

The study was carried out between July and December 2010. All the consenting post-partum women in the hospital in the department of gynecology and obstetrics were included in the study. Women who refused to participate in the study were excluded. Women were discharged after counseling and followed up after 3 months in FP OPD and those who continued with postpartum IUCD or were using contraceptive as told by them before discharge from hospital were included in the list of postpartum contraceptive acceptors.

Impact of counseling was seen by observing difference in number of women who accepted to use any of the recommended contraceptive method before and after counseling and their adherence to that contraceptive crosschecked at their follow up visit at 3 months.

According to the NFHS-3 data, the prevalence rate of contraceptive use among the currently married women who have ever used any contraceptive method was 55 per cent. The present sample calculated-for the relative precision of 10 per cent was 328 . The randomization was done at the patient level, considering the design effect as 1.5 per cent, a-final, sample size of 492 (328 x 1.5) was considered for analysis.

A semi structured interview schedule was prepared. The interview schedule was pre-tested in few post-partum women which were not included in the study and the revised version of the interview schedule was administered to the study population. Modified Kuppuswamy socio-economic scale was used to ascertain the socio-economic status of the family. Earlier use of different contraceptive methods among subjects was defined as use of contraceptive methods in the past one year proceeding the study period. If more than one method was used, then the latest contraceptive method used was taken into account.

The women were explained about the objectives of the study and an informal written consent was obtained. All women, both participants as well as non-participants in the study were offered health education, counseling, 
contraceptive and referral services. Data was analyzed with the help of SPSS version 16.0.

\section{RESULTS}

A total of 492 eligible women were included in the study. The mean age of the women was $24.7 \pm 3.7$ years. Majority of the respondents $(51.6 \%)$ were in the age group of 15-24 years. Most of them were (70.7\%) were literate and that too maximum were $8^{\text {th }}$ pass. Majority (78.7\%) had family income less than Rs. 5000 per month. Majority of the respondents were Hindus $(93.1 \%)$ by religion and most of the respondents were from urban slums of Delhi. Most of the women (51.8\%) had only one living issue and most of them $(83.7 \%)$ were housewives (Table 1).

Table 1: Sociodemographic profile of women under study.

\begin{tabular}{|c|c|c|}
\hline & Number & Percentage \\
\hline \multicolumn{3}{|l|}{ Age (years) } \\
\hline $15-24$ & 254 & 51.6 \\
\hline $25-35$ & 223 & 45.4 \\
\hline$>35$ & 15 & 3.0 \\
\hline \multicolumn{3}{|l|}{ Educational status } \\
\hline Illiterate & 144 & 29.3 \\
\hline$<$ less than $8^{\text {th }}$ & 38 & 7.7 \\
\hline $8^{\text {th }}$ pass & 140 & 28.5 \\
\hline $10^{\text {th }}$ pass & 107 & 21.7 \\
\hline $12^{\text {th }}$ pass & 39 & 7.9 \\
\hline Graduate and higher & 24 & 4.9 \\
\hline \multicolumn{3}{|l|}{ Occupation } \\
\hline Housewife & 412 & 83.7 \\
\hline Working & 80 & 16.3 \\
\hline \multicolumn{3}{|c|}{ Family income p.m. } \\
\hline$<2000$ Rs. & 201 & 40.9 \\
\hline 2000-5000 Rs. & 182 & 37.0 \\
\hline 5000-10000 Rs. & 86 & 17.5 \\
\hline$>10000$ Rs. & 23 & 4.6 \\
\hline \multicolumn{3}{|l|}{ Residence } \\
\hline Urban slum & 441 & 89.7 \\
\hline Urban non slum & 40 & 8.1 \\
\hline Rural & 11 & 2.2 \\
\hline \multicolumn{3}{|l|}{ Parity } \\
\hline 1 & 255 & 51.8 \\
\hline 2 & 162 & 32.9 \\
\hline 3 & 54 & 11.0 \\
\hline$\geq 4$ & 21 & 4.3 \\
\hline \multicolumn{3}{|l|}{ Religion } \\
\hline Hindu & 458 & 93.1 \\
\hline Muslim & 28 & 5.7 \\
\hline Others & 6 & 1.2 \\
\hline
\end{tabular}

As seen from Table 2, Frequency of earlier use of contraception was highest in age group 25-35 years. Awareness and acceptance after post-partum counselling increased with age (statistically non-significant). Awareness and acceptance after counselling was found to be highest among women with graduate or higher education, higher socio economic status and working women. Highest acceptance was seen among women with children.

Table 2: Showing awareness, earlier use and acceptance per socio demographic profile.

\begin{tabular}{|c|c|c|c|c|}
\hline $\begin{array}{l}\text { Name of } \\
\text { socio- } \\
\text { demographic } \\
\text { factor }\end{array}$ & $\begin{array}{l}\text { Total } \\
(492)\end{array}$ & $\begin{array}{l}\text { Awareness } \\
\text { (373) }\end{array}$ & $\begin{array}{l}\text { Earlier } \\
\text { use (105) }\end{array}$ & $\begin{array}{l}\text { Acceptance } \\
(280)\end{array}$ \\
\hline \multicolumn{5}{|l|}{ Age (years) } \\
\hline $15-24$ & 254 & $191(75.2)$ & $40(15.7)$ & $138(54.3)$ \\
\hline $25-35$ & 223 & $170(76.2)$ & $65(29.5)$ & $132(59.2)$ \\
\hline$>35$ & 15 & $12(80.0)$ & $0(0.0)$ & $10(66.7)$ \\
\hline $\mathrm{P}$ value & & 0.897 & 0.000 & 0.418 \\
\hline \multicolumn{5}{|c|}{ Educational status } \\
\hline Illiterate & 144 & $72(50.0)$ & $16(11.1)$ & $55(38.2)$ \\
\hline$<$ less than $8^{\text {th }}$ & 38 & $30(78.9)$ & $9(23.7)$ & $23(60.5)$ \\
\hline $8^{\text {th }}$ pass & 140 & $120(85.7)$ & $30(21.4)$ & $78(55.7)$ \\
\hline $10^{\text {th }}$ pass & 107 & $93(86.9)$ & $19(17.8)$ & $75(70.1)$ \\
\hline $12^{\text {th }}$ pass & 39 & $34(87.2)$ & $19(48.7)$ & $29(74.4)$ \\
\hline $\begin{array}{l}\text { Graduate and } \\
\text { higher }\end{array}$ & 24 & $24(100.0)$ & $12(50)$ & $20(83.3)$ \\
\hline $\mathrm{P}$ value & & 0.000 & 0.000 & 0.000 \\
\hline \multicolumn{5}{|c|}{ Family income p.m. } \\
\hline$<2000$ Rs. & 201 & $157(78.1)$ & $34(16.9)$ & $123(61.2)$ \\
\hline $\begin{array}{l}2000-5000 \\
\text { Rs. }\end{array}$ & 182 & $130(71.4)$ & $39(21.4)$ & $82(45.1)$ \\
\hline $\begin{array}{l}5000-10000 \\
\text { Rs. }\end{array}$ & 86 & $66(76.7)$ & $21(24.4)$ & $57(66.3)$ \\
\hline$>10000$ Rs. & 23 & $20(87.7)$ & $11(47.8)$ & $18(78.3)$ \\
\hline P value & & 0.253 & 0.006 & 0.000 \\
\hline \multicolumn{5}{|l|}{ Residence } \\
\hline Urban slum & 441 & $333(75.5)$ & $95(21.5)$ & $245(55.6)$ \\
\hline $\begin{array}{l}\text { Urban non } \\
\text { slum }\end{array}$ & 40 & $34(85.0)$ & $8(20.0)$ & $29(72.5)$ \\
\hline Rural & 11 & $5(45.5)$ & $2(18.1)$ & $6(54.5)$ \\
\hline $\mathrm{P}$ value & & 0.025 & 0.191 & 0.122 \\
\hline \multicolumn{5}{|l|}{ Parity } \\
\hline 1 & 255 & $182(71.4)$ & 35 (13.7) & $132(51.8)$ \\
\hline 2 & 162 & $131(80.9)$ & $50(30.9)$ & $109(67.3)$ \\
\hline 3 & 54 & $45(83.3)$ & $18(33.3)$ & $31(57.4)$ \\
\hline$\geq 4$ & 21 & $15(71.4)$ & $2(9.5)$ & $8(38.1)$ \\
\hline $\mathrm{P}$ value & & 0.076 & 0.000 & 0.005 \\
\hline \multicolumn{5}{|l|}{ Occupation } \\
\hline Housewife & 412 & $298(72.3)$ & $70(16.9)$ & $215(52.0)$ \\
\hline Working & 80 & $75(93.8)$ & $35(43.8)$ & $65(81.0)$ \\
\hline $\mathrm{P}$ value & & 0.003 & 0.000 & 0.001 \\
\hline \multicolumn{5}{|l|}{ Religion } \\
\hline Hindu & 458 & $346(75.8)$ & $101(22.1)$ & $257(56.1)$ \\
\hline Muslim & 28 & $21(71.4)$ & $4(14.3)$ & $20(71.4)$ \\
\hline Others & 6 & $4(66.7)$ & $0(0.0)$ & $3(50.0)$ \\
\hline $\mathrm{P}$ value & & 0.331 & 0.273 & 0.267 \\
\hline
\end{tabular}


Majority had awareness regarding terminal method of contraception and least for injectables (Figure 1). The decision maker for use of contraception was husband $(48 \%)$ in majority of women (Figure 2$)$. The main reason for non-acceptance of male child and anxiety about side effects (Figure 2).

Table 3: Reasons for non-acceptance $(n=212)$.

\begin{tabular}{|ll|}
\hline Reasons & \% Distribution \\
\hline Not acceptable to husband/family & 2 \\
\hline $\begin{array}{l}\text { Family not complete/wants more } \\
\text { children }\end{array}$ & 6 \\
\hline Expectation of a male child & 22 \\
\hline No Knowledge of source & 6 \\
\hline Anxiety about side effects & 24 \\
\hline No need,rely on natural methods & 12 \\
\hline Breast feeding & 10 \\
\hline Wants to delay till end of puerperium & 10 \\
\hline
\end{tabular}

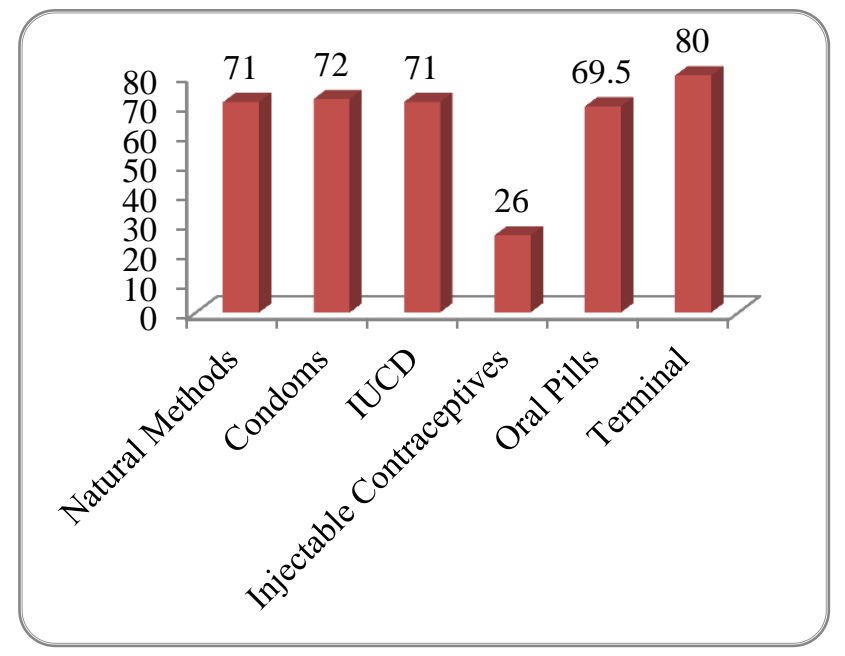

Figure 1: Showing awareness and acceptance of the various contraceptive methods $(\%)$.

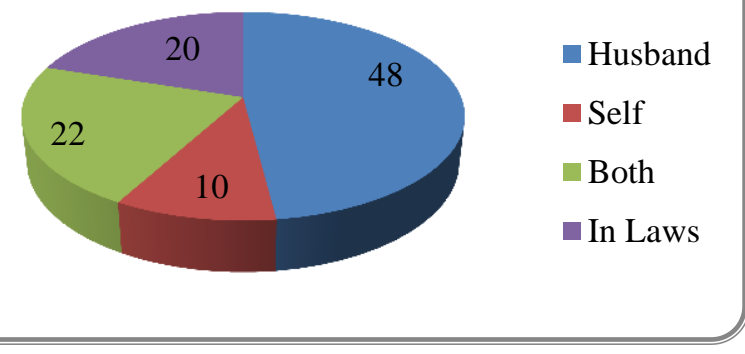

Figure 2: Depicting proportion of decision makers for the use of contraception $(\%)$.

\section{DISCUSSION}

About $3 / 4^{\text {th }}$ of the total women $(75.8 \%$ ) had heard of at least one of the modern contraceptive methods, which are included in National Family Planning programme (Figure 1) but only $21.3 \%$ had ever used any of them while $54.5 \%$ women had the knowledge regarding contraceptive method but never used. It is comparable to another study by Srivastava et al. in U.P. ${ }^{18}$ But awareness is found very high compared to only $8 \%$ in Young et al.'s study conducted in Auckland. ${ }^{19}$ The rest of the $1 / 4^{\text {th }}$ of respondents were neither aware nor used any of the contraceptive methods at all.

The prevalence of the contraception among women was found to be $21.3 \%$ in contrast to National family health survey 3 reports $^{8}(56.3 \%)$ but comparable to another study conducted among slum dwellers in Delhi $(25 \%){ }^{20}$ This low prevalence may be due to the fact that a major part of respondents belong to urban slums of Delhi.

The maximum awareness was for tubectomy (80\%) comparable to that of NFHS $3(98 \%)^{8}$ as well as to a survey on knowledge, attitude and practice of contraception conducted in U.P. $(82.1 \%){ }^{18}$

The contraception acceptance showed rising trend with the increasing age, educational status and family income (Table 2). Our study showed that with increasing socio economic status there was an increase in the awareness and use of the contraceptive methods. This is similar to the findings of a study conducted in south Delhi ${ }^{21}$ and in resettlement colony of Delhi. ${ }^{22}$

After counseling in immediate postpartum period, the contraceptive acceptance was found to be $56.9 \%$ comparable to a prospective cross sectional study by Romero et al. $(50 \%)^{23}$ as well as to NFHS $3(56.3 \%$ prevalence) but higher than a Sri Lankan study published in 2009 which found contraceptive practice to be only $41.1 \%$ among 129 mothers interviewed. ${ }^{24}$ However, a study from Turkey showed a much higher (76\%) contraceptive use in postpartum women. ${ }^{25}$

The study revealed a significant rise of $35.6 \%$ in number of family planning acceptors as a result of family planning counseling services to the post-partum women prior to discharge from hospital similar to a study performed by medina et al $(10$ to $33 \%){ }^{26}$ There was a change in trend of methods previously used and now accepted. Percentage of condom users declined from $44 \%$ to $8 \%$, pills from $35 \%$ to $10 \%$, while IUD users increased from $11 \%$ to $45 \%$ and injectables from 10 to $15 \%$. The explanation to this change was that women wanted non dependence on husband as well as reliable, long term method with no stress of daily pills. Almost $3 / 4^{\text {th }}$ of the contraceptive acceptors selected temporary spacing methods while only $22 \%$ accepted terminal method of sterilization. Although this may not bring down the family size but will significantly reduce the population burden/stabilize the population. Studies have demonstrated that even if there is reduction in family size of individual couples, delaying childbearing will bring about a decline in fertility and population growth rate. ${ }^{27}$ 
Terminal method was accepted mainly by those with 3 or more children.

In $48 \%$ of women, husband was the decision maker, so husband was playing an important and pivotal role in family planning acceptance (Figure 2). Therefore, there is need for counseling sessions for couples as a whole and this opportunity can be very well sought in women seeking hospital deliveries.

Both the contraceptive awareness and postpartum acceptance of family planning methods showed a positive correlation with the number of live children.

Even after counseling, $43.1 \%$ women did not accept to choose any of the suggested contraceptive methods. The main reasons for non-acceptance were expectation of a male child and fear of side effects similar to few other studies of Delhi, Pakistan, Chandigarh etc. ${ }^{21,28,29}$ In another study of Delhi, $35.9 \%$ of the non-acceptors did not use any method due to ignorance and lack of communication. $^{12}$

The present study highlights the need to strengthen IEC activities and Family planning services to be provided in immediate post-partum period before discharge of women from the hospital to ensure the contraceptive acceptance and its use among them. This would curb unwanted pregnancies which lead to unsafe abortion and contributes to maternal mortality. We recommend sustained efforts to increase awareness and motivation for contraceptive use. This can be brought about by facilitating the access to more information, education and communication with the immediate postpartum women and improved social and welfare services. The most important factor is regular availability of contraceptives and adequate health care services even at the peripheral level.

Education of masses, upliftment of economic standards, strong political commitment, effective health care system, change in the knowledge, attitude and practice of contraception as a whole constitute important factors in increasing acceptance and usage of spacing and contraception.

Funding: No funding sources Conflict of interest: None declared

Ethical approval: The study was approved by the appropriate independent ethics committee

\section{REFERENCES}

1. New Delhi: Registrar General \& Census Commissioner of India. Census of India, 2011. Available at: http://censusindia.gov.in/.

2. Smith R, Ashford L, Gribble J, Clifton D. Family planning saves lives. In: Smith R, Ashford L, Gribble J, Clifton D, eds. A Report. Washington, DC: Population Reference Bureau; 2009.
3. Conde-Agudelo A, Belizan JM. Maternal morbidity and mortality associated with inter-pregnancy interval: cross sectional study. $\mathrm{Br}$ Med $\mathrm{J}$. 2000;321(7271):1255-9.

4. Collumbien M, Gerressu M, Clenland J. Nonuse and use of ineffective methods of contraception. In comparative qualification of health risks: global and regional burden of disease attributable to selected major factors. In: WHO, eds. WHO, Chapter 15. Geneva: World health organization; 2004: 12551320.

5. World Health Organization (WHO). Maternal mortality in 2005. In: WHO, eds. Estimates Developed by WHO, UNICEF, UNFPA and the World Bank. Geneva: WHO; 2007.

6. Shah IH, Say L. Maternal mortality and maternity care from 1990 to 2005: uneven but important gains. Reprod Health Matters. 2007;15(30):17-27.

7. United Nations Interagency Group for Child Mortality Estimation. Levels \& trends in child mortality. In: UNCF's eds. A Report. New York: United Nations Children's Fund; 2011.

8. International Institute for Population Sciences (IIPS) and Macro International. National family health survey (NFHS-3), 2005-06. In: IIPS's eds. IIPS Survey. Vol. 1. Mumbai, India: IIPS; 2007.

9. Rutstein S. Relationships between pregnancy intervals and prenatal mortality: proceedings of the $2^{\text {nd }}$ champions meeting on birth spacing. In: Rutstein S, eds. A Meeting. Washington, DC: CATALYST Consortium; 2002: 15-22.

10. Setty-Venugopal V, Upadhyay UD. Birth spacing. Three to five saves lives. In: Setty-Venugopal V, Upadhyay UD, eds. Population Reports. Series L, No. 13. Baltimore: Johns Hopkins University; 2002.

11. Whitworth A, Stephenson R. Birth spacing, sibling rivalry and child mortality in India. Soc Sci Med. 2002;55(12):2107-19.

12. Winikoff $B$. The effects of birth spacing on child and maternal health. Stud Fam Plann. 1983;14(10):23145.

13. Charles W, Ann P. Alternative measure for unmet need for family planning in developing countries. Int Fam Plan Perspect. 2000;7(4):126-35.

14. Ashoke S, John S, Jayanti MT. The KAP-Gap in Nepal: reasons for non-use of contraception among couples with an unmet need for family planning. Asia-Pac Popul J. 2000;6(1):25-38.

15. Levitt C, Shaw E, Wong S, Kaczorowski J, Springate R, Sellors J, et al. McMaster University Postpartum Research Group. Systematic review of the literature on postpartum care: Selected contraception methods, postpartum Papanicolaou test and rubella immunization. Birth. 2004;31:203-12.

16. Levine R, Langer A, Birdsall N, Matheny G, Wright M, Bayer A. Contraception. In: Jamison DT, Breman JG, Measham AR, eds. Disease Control. Priorities in Developing Countries. 5th ed. New York: Oxford University Press; 2006: 1075-1090. 
17. Lule E, Singh S, Chowdhury SA. Fertility regulation behaviors and their costs: contraception and unintended pregnancies in Africa and Eastern Europe \& Central Asia. In: Lule E, Singh S, Chowdhury SA, eds. A Report. Washington DC, USA: HNP Publication, World Bank; December 2007.

18. Srivastava R, Srivastava D, Jina R, Srivastava K, Sharma N, Saha S. Contraceptive knowledge attitude and practice (KAP) survey. J Obstet Gynecol India. 2005 Nov/Dec;55(6):546-55.

19. Young LK, Farguhar CM, McCowan LM, Roberts HE, Taylor J. The contraceptive practice of women seeking termination of pregnancy in an Aukland clinic. NZ Med J. 1994;107:189-91.

20. Ingle GK, Avdhesh K, Singh S, Gulati N. Reasons for non-acceptance of contraceptive methods among Jhuggi-Jhompri dwellers of Delhi. Indian J Prev Soc Med. 1999;30(1):32-7.

21. Sharma AK, Graver V, Agarwal OP, Dubey KK. Pattern of contraceptive use by residents of a village in South Delhi. Indian J Public Health. 1997;41(3):75-8.

22. Patro BK, Kant S, Baridalyne N, Goswami AK. Contraceptive practice among married women in a resettlement colony of Delhi. Health Popul Perspect Issues. 2005;28(1):9-16.

23. Romero-Gutierrez G, Garcia-Vazquez MG, HuertaVarge LF, Ponce-Ponce De Leon AL. Postpartum contraceptive acceptance in Leon, México: a multivariate analysis. Eur J Contracept Reprod Health Care. 2003;8(0.4):210-16.
24. Agampodi SB, Agampodi TC, Chandrasekara P. Family planning prevalence among postpartum mothers attending child welfare clinics - a Sri Lankan experience. Indian J Community Med. 2009;34:265-6.

25. Vural B, Vural F, Erk A, Karabacak O. Knowledge on lactational amenorrhoea and contraception in Kocaeli, Turkey. East Afr Med J. 1999;76:385-9.

26. Medina R, Lundgren R, Mendoza I. Strengthening of the postpartum and postabortion family planning program of the Escuela Hospital. In: Medina R, Lundgren R, Mendoza I, eds. Final Report. Tegucigalpa, Honduras: Ministry of Health and INOPAL III/Population Council; August 1998.

27. Rajaretham T. How delaying marriage and spacing births contribute to population control: an explanation with illustrations. J Fam Welfare. 1990;34:3-13.

28. Humayun S. Knowledge and practices of family planning in Grahdmultipara. Coll Physicians Surg. 2002;12(9):522-5.

29. Singh K, Swami HM, Dhawan S, Bhatia SPS. A study of family planning practices in rural areas of Chandigarh. Indian J Prev Soc Medt. 1999;30(324):107-10.

DOI: 10.18203/2320-1770.ijrcog20150075

Cite this article as: Singh M, Mehla S, Ranjan R, Das B. Awareness and acceptance of contraception in postpartum women in a tertiary care hospital of Delhi. Int $\mathbf{J}$ Reprod Contracept Obstet Gynecol 2015;4:690-5. 